\title{
On the impact of wave-like disturbances on turbulent fluxes and turbulence statistics in nighttime conditions: a case study
}

\author{
D. J. Durden ${ }^{1}$, C. J. Nappo ${ }^{2}$, M. Y. Leclerc ${ }^{1}$, H. F. Duarte ${ }^{1}$, G. Zhang ${ }^{1}$, M. J. Parker ${ }^{3}$, and R. J. Kurzeja ${ }^{3}$ \\ ${ }^{1}$ The University of Georgia, Lab for Environmental Physics, Griffin, GA 30223, USA \\ ${ }^{2}$ CJN Research Meteorology, Knoxville, TN 37919, USA \\ ${ }^{3}$ Savannah River National Laboratory, Aiken, SC 29802, USA
}

Correspondence to: M. Y. Leclerc (mleclerc@uga.edu)

Received: 7 December 2012 - Published in Biogeosciences Discuss.: 14 March 2013

Revised: 12 November 2013 - Accepted: 18 November 2013 - Published: 23 December 2013

\begin{abstract}
The interpretation of flux measurements in nocturnal conditions is typically fraught with challenges. This paper reports on how the presence of wave-like disturbances in a time series, can lead to an overestimation of turbulence statistics, errors when calculating the stability parameter, erroneous estimation of the friction velocity $u *$ used to screen flux data, and errors in turbulent flux calculations. Using time series of the pressure signal from a microbarograph, wavelike disturbances at an AmeriFlux site are identified. The wave-like disturbances are removed during the calculation of turbulence statistics and turbulent fluxes. Our findings suggest that filtering eddy-covariance data in the presence of wave-like events prevents both an overestimation of turbulence statistics and errors in turbulent flux calculations. Results show that large-amplitude wave-like events, events surpassing three standard deviations, occurred on $18 \%$ of the nights considered in the present study. Remarkably, on flux towers located in a very stably stratified boundary-layer regime, the presence of a gravity wave can enhance turbulence statistics more than $50 \%$. In addition, the presence of the disturbance modulates the calculated turbulent fluxes of $\mathrm{CO}_{2}$ resulting in erroneous turbulent flux calculations of the order of $10 \%$ depending on averaging time and pressure perturbation threshold criteria. Furthermore, the friction velocity $u *$ was affected by the presence of the wave, and in at least one case, a $10 \%$ increase caused $u *$ to exceed the arbitrary $0.25 \mathrm{~m} \mathrm{~s}^{-1}$ threshold used in many studies. This results in an unintended bias in the data selected for analysis in the flux calculations. The impact of different averaging periods was also examined and found to be variable specific. These early case study results provide an insight into errors intro-
\end{abstract}

duced when calculating "purely" turbulent fluxes. These results could contribute to improving modeling efforts by providing more accurate inputs of both turbulent kinetic energy, and isolating the turbulent component of $u *$ for flux selection in the stable nocturnal boundary layer.

\section{Introduction}

While the eddy-covariance technique measures fluxes of momentum and scalars accurately in well-mixed convective boundary layer conditions, challenges in the measurement of net ecosystem exchange in the stable nocturnal boundary layer have been reported (Aubinet, 2010; Falge et al., 2001; Goulden et al., 1996; Karipot et al., 2008; Mahrt, 1999, 2010; Mathieu et al., 2005). One challenge that must be encountered when conducting eddy-flux measurements in a stable boundary layer is the presence of wave-like disturbances (Nappo et al., 2008). Though the properties and propagation of wave-like disturbances in the boundary layer have been extensively studied (Chimonas, 1993, 1999; Einaudi and Finnigan, 1981, 1993; Einaudi et al., 1984; Finnigan and Einaudi, 1981; Hooke et al., 1973; Nappo, 2002), scant attention has been given to the impact of waves on turbulence and turbulent fluxes (Nappo et al., 2008; Viana et al., 2009; Zeri and Sa, 2010).

Waves are ubiquitous in the nocturnal boundary layer (Gossard and Hooke, 1975; Grivet-Talocia et al., 1999; Nappo, 2002; Rees et al., 2000) and can be generated by a number of mechanisms, including thunderstorms (Gedzelman, 1983), orographic excitation (terrain induced) 
(Chimonas, 1993), and shear instability (Emmanuel, 1973; Hooke et al., 1973). Ducted waves are bound between the ground surface and some atmospheric reflecting layer above or two reflecting critical layers aloft (Cooper et al., 2006; Fritts et al., 2003; Newsom and Banta, 2003; Rees and Mobbs, 1988), thus producing a wave guide allowing propagation to occur over long distances and time periods. This implies a large-amplitude wave-like event could have wideranging impacts.

Gravity waves and turbulence can easily be mistaken in turbulence statistics and fluxes due to the absence of a welldefined spectral gap between waves and turbulence (Finnigan, 1999; Viana et al., 2009). When no clear spectral gap is present, the wave signal should be removed to prevent errors in turbulence statistics (Nappo et al., 2008; Viana et al., 2009). In addition, van Gorsel et al. (2011) found that the presence of gravity waves introduces large random errors in the change in storage and advection terms in mass balance calculations.

This paper reports on a case study examining the impact of large-amplitude wave-like events on turbulence variables and turbulent fluxes. A determination of the frequency of largeamplitude wave-like disturbances in the pressure signal will be assessed. A triple decomposition of eddy-covariance data is used to identify waves in the original signal (Hauf et al., 1996; Nappo et al., 2008). The magnitude of the overestimation (inflation) in turbulence statistics and errors in turbulent flux calculations due to the presence of wave events is presented for two nights in contrasting atmospheric conditions. The variation of the wave signal and subsequent impact on both turbulence parameters and turbulent fluxes are evaluated as a function of measurement level and different averaging times.

\section{Measurements}

\subsection{Site description}

Turbulence and eddy-covariance data were obtained from a tall tower with instrumentation located at 34, 68, and $329 \mathrm{~m}$ at the Aiken AmeriFlux site located near Beech Island, South Carolina, USA $\left(33^{\circ} 24^{\prime} 21^{\prime \prime} \mathrm{N}, 81^{\circ} 50^{\prime} 02^{\prime \prime} \mathrm{W}\right)$. The tower is positioned on a rural ridge, at an elevation of $\sim 116 \mathrm{~m}$, overlooking a mixture of mixed pine forests and agricultural fields. Each eddy-flux system consisted of a fast-response omnidirectional three-dimensional sonic anemometer (Applied Technologies, Inc., Longmont, CO, model Sx (34 m level) and model A (68 and $329 \mathrm{~m}$ levels)) and a fast-response open path $\mathrm{CO}_{2} / \mathrm{H}_{2} \mathrm{O}$ gas analyzer (Li-Cor Biosciences, Lincoln, NE, model 7500). Measurements were collected at $10 \mathrm{~Hz}$.

To detect wave-like activity, a microbarograph (Setra Systems, Boxborough, MA, Model 270) with static pressure disks (Vaisala, Helsinki, Finland, model SPH10) was used to measure static atmospheric pressure at the surface. The pressure transducer continuously collected data at $20 \mathrm{~Hz}$ to a data logger (Campbell Scientific, Logan, UT, model CR5000) located at the base of the tall tower. The data were averaged to $0.1 \mathrm{~Hz}$ for the purpose of wavelet analyses.

\subsection{Signal processing of microbarograph data}

A challenge in analyzing turbulent fluxes in the presence of wave-like disturbances resides in the recognition and subsequent separation of the wave from the turbulence signal (Finnigan, 1988). Previous studies used phase averaging to separate waves from turbulence (Einaudi and Finnigan, 1981, 1984, 1993; Finnigan and Einaudi, 1981). However, phase averaging requires a monochromatic wave that persists for more than several cycles, a rare occurrence in the nocturnal boundary layer (hereafter referred to as "NBL"). Given the non-monochromatic nature of the disturbances, the method applied by Hauf et al. (1996) and Nappo et al. (2008) using band-pass filtering to separate waves from turbulence was used.

The first step in the analysis consists of identifying periods of wave-like activity using surface based static atmospheric pressure data. Wave-like perturbations are most readily detectable in the static pressure signal, in comparison the wave signal is not as strong in the velocity components and other scalars and can be hard to distinguish from turbulence. To detect large-amplitude events, the static pressure signal from 00:00 to 06:00 local time (LT) each night was bandpass filtered, using a ramped Butterworth filter, so that the residual signal was composed of frequencies corresponding to contributions from 3 to $30 \mathrm{~min}$ periods. Our analysis focuses on shorter period disturbances since the timescales are smaller than the typical timescale used for flux calculations (30 min). Following Nappo et al. (2008), flux and turbulent statistical averages calculated shorter than the wave period did not greatly affect calculations; therefore, this study focuses on events with a period less than $30 \mathrm{~min}$. The standard deviation $\left(\sigma_{\mathrm{p}}\right)$ of the static pressure was calculated from this residual signal and used to determine a detection threshold for large-amplitude events. Wavelet analysis of band-pass filtered surface pressure data is used to determine time, duration, and period/frequency ranges of wave-like activity. The Morlet wavelet was chosen in our study for its high resolution in frequency space, the Gaussian-damped sine wave is well suited for the determination of the period/frequency range of wave events (Nappo, 2002; Torrence and Compo, 1998).

\subsection{Signal processing of eddy-covariance data}

Once the frequency range of the wave, its duration, and the start time of the individual wave episodes are determined, the eddy-covariance data are then detrended and band-pass filtered. The data are band-pass filtered using a ramped Butterworth filter to resolve the wave-like perturbations of wind 
components $(u, \mathrm{v}$, and $w)$, temperature, water vapor, and carbon dioxide. This process is repeated for each variable at each of the three levels on the tower. The $10 \mathrm{~Hz}$ eddycovariance data selected include one hour before and after the wave event in the band-pass filter to prevent edge effects from being introduced into the turbulence and flux calculations. A three-dimensional rotation, forcing the vertical and lateral wind components to zero, was performed on the entire time series (i.e., a four hour period) before filtering the three wind components. These wave perturbations are then removed from the original time series, and the remaining signal is considered to be the "true" turbulence signal. The original unfiltered signal is referred to as the "wave inflated" signal. Therefore, a triple decomposition of a given variable $q(z, t)$ is performed as follows:

$q(z, t)=\bar{q}(z)+q^{\prime}(z, t)+\widetilde{q}(z, t)$,

where the terms on the right-hand side represent the mean, turbulence, and wave components, respectively. If the wave signals are not removed, then the resulting flux would be

${\overline{w^{\prime} q^{\prime}}}^{\text {original }}=(w-\bar{w})^{-}(q-\bar{q})$.

Using this triple decomposition on $w$ and $q$, the vertical flux of $q$ is given by

${\overline{w^{\prime} q^{\prime}}}^{\text {corrected }}=\overline{(w-\bar{w}-\widetilde{w})(q-\bar{q}-\widetilde{q})}$,

where Eq. (3) is the turbulent flux with the wave signals removed taken to be the true Reynolds flux. The Webb, Pearman, and Leuning (1980) correction was applied to flux measurements, for both the original flux signal and the wave corrected signal. This process illustrates the effect of a gravity wave on fluxes calculated in the customary way, such as with an automated routine.

\section{Results and discussion}

\subsection{Large-amplitude wave-like events}

Only large-amplitude events in the pressure data were investigated in this study, and the standard deviation of the static pressure $\left(\sigma_{\mathrm{p}}\right)$ was calculated to identify these events. Table 1 tabulates the average monthly values for $\sigma_{\mathrm{p}}$ using nighttime data (00:00-06:00 LT). It can clearly be seen that the frequency and intensity of large-amplitude pressure events increased dramatically in the winter months, when stable conditions persist longer.

After calculating $\sigma_{\mathrm{p}}$ the data were assessed to determine a reasonable threshold for events that would be significantly large, a $3 \sigma_{\mathrm{p}}$ threshold was chosen to include the events that would have the most impact on turbulence statistics and flux calculations. However, the number of events surpassing $2 \sigma_{\mathrm{p}}$ was calculated as well. Assuming that $\sigma_{\mathrm{p}}$ is calculated over a long enough period to provide a normal distribution, using a $3 \sigma_{\mathrm{p}}$ threshold would render only the top $0.3 \%$ of cases as large-amplitude events. However, the nature of the wave-like disturbances is such that the peaks of the waves are the major contributing factors to the large $\sigma_{\mathrm{p}}$ and the majority of the body of the wave falls within a single standard deviation. Furthermore, waves of smaller amplitudes are difficult to resolve in the eddy-covariance data. The wave signal is not as pronounced in the velocity components and scalars as observed in the pressure signal. Therefore, the larger $3 \sigma_{\mathrm{p}}$ threshold was chosen for this preliminary study.

The number of large-amplitude wave-like events was determined for the period 22 April 2009-30 March 2010. Using the wavelet transform, events were deemed wave like by assessing the duration of the event in relation to the period of the event to determine if the disturbance exhibited a cyclic nature, similar to the selection criterion used in Hauf et al. (1996). The monthly distribution of nights with wavelike events surpassing $3 \sigma_{\mathrm{p}}$ and $2 \sigma_{\mathrm{p}}$ thresholds is presented in Table 1. During this period, 127 days were disregarded due to rain or erroneous data. Large-amplitude pressure fluctuations often occurred on nights with rain; therefore, the nights with rain were removed when calculating the standard deviation. At least one large-amplitude wave-like event surpassing a $3 \sigma_{\mathrm{p}}$ threshold occurred during 38 of the remaining 216 nights or $\sim 18 \%$ of the nights assessed. Using a $2 \sigma_{\mathrm{p}}$ threshold would result in $39 \%$ of nights containing at least one event.

Wave-like motions were observed on most of the 216 nights examined; however, the amplitude of the event was either small or the period of the wave event was larger than the period of interest $(30 \mathrm{~min})$. Two nights with large-amplitude wave-like events, 23 April 2009 and 3 December 2009, were selected for this study to evaluate wave contributions to turbulence statistics and flux calculations for contrasting nights, one quiescent and one turbulent night. These two nights were also selected due to the contrasting atmospheric stabilities, the rather large amplitude of the events, and wave propagation occurred up to the highest measurement level on the tall tower.

\subsection{Characterizing the wave events}

The morning hours (00:00 to 06:00 LT) of 23 April 2009 and 3 December 2009 exhibited well-defined wave episodes as shown in Fig. 1. Increases in wavelet energy density during periods of wave-like activity are used to identify both wave period and duration. Between 02:30 and 04:30 LT on 23 April 2009, one wave disturbance occurred with an approximate period of $7 \mathrm{~min}$ and another with an approximate period of 4 min. On 3 December 2009, a wave disturbance between 03:30 and 05:30 LT occurred with an approximate period of $8 \mathrm{~min}$ and another with an approximate period of $12 \mathrm{~min}$. Both nights consisted of multiple events that persisted only a few cycles with varying amplitudes. The average wave 
Table 1. Standard deviation of surface static pressure $\sigma_{\mathrm{p}}$ and the monthly distribution of nights with $3 \sigma \mathrm{p}$ and $2 \sigma \mathrm{p}$ wave-like events.

\begin{tabular}{lrrrr}
\hline Month & $\begin{array}{r}\text { Nights of available } \\
\text { data without rain }\end{array}$ & $\begin{array}{r}\text { Standard deviation } \\
\text { of pressure } \sigma_{\mathrm{p}}\end{array}$ & $\begin{array}{r}\text { Nights with } 3 \sigma_{\mathrm{p}} \\
\text { wave-like events }\end{array}$ & $\begin{array}{r}\text { Nights with } 2 \sigma_{\mathrm{p}} \\
\text { wave-like events }\end{array}$ \\
\hline Apr & 9 & 0.0159 & 1 & 2 \\
May & 23 & 0.0221 & 3 & 8 \\
Jun & 9 & 0.0171 & 0 & 2 \\
Jul & - & - & - & - \\
Aug & 29 & 0.0207 & 2 & 7 \\
Sep & 12 & 0.0185 & 0 & 1 \\
Oct & 25 & 0.0283 & 3 & 9 \\
Nov & 12 & 0.0213 & 0 & 1 \\
Dec & 21 & 0.0403 & 12 & 19 \\
Jan & 24 & 0.0301 & 7 & 8 \\
Feb & 26 & 0.0310 & 4 & 10 \\
Mar & 26 & 0.0281 & 4 & 84 \\
\hline Total & 216 & 0.0265 & 38 & \\
\hline
\end{tabular}
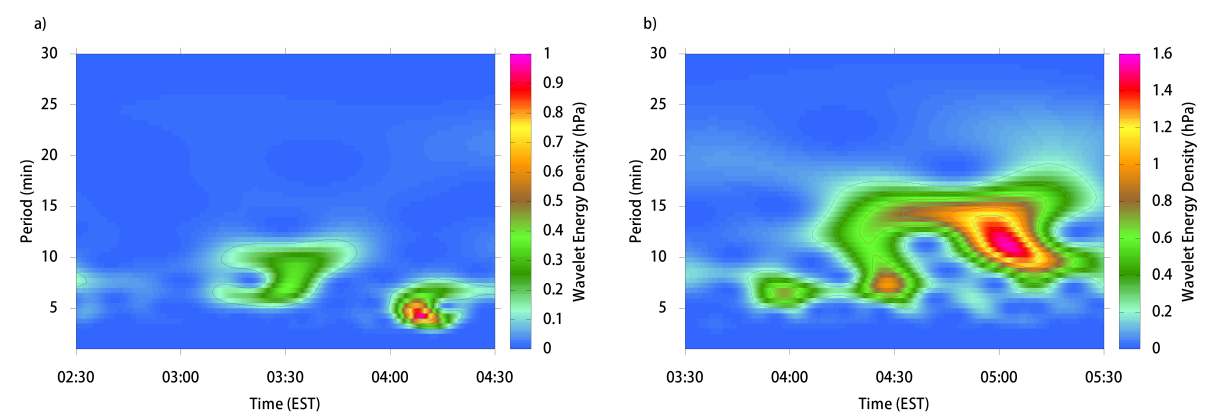

Fig. 1. Wavelet analysis of surface static pressure data from the microbarograph sensor for (a) 23 April 2009 and (b) 3 December 2009.

periods and durations of these selected episodes was $5.5 \mathrm{~min}$ from 02:30 to 04:30 LT on 23 April 2009 and $10 \mathrm{~min}$ from 03:30 to 05:30 LT on 3 December 2009. The two case study nights are summarized in Table 2.

Since the wave introduces an error in the analysis of the time series overestimating turbulence properties, it follows that an uncorrected signal will lead to errors being introduced throughout all calculations, including the flux Richardson number and the friction velocity $(u *)$. Thus, the nights are characterized by the Brunt-Väisälä frequency $(N)$ calculated as follows:

$N=\sqrt{\frac{g}{\overline{T_{\mathrm{v}}}} \frac{\partial \theta}{\partial z},}$

and the Richardson number $(R i)$ derived as

$R i=\frac{N^{2}}{\left(\frac{\partial U}{\partial z}\right)^{2}+\left(\frac{\partial V}{\partial z}\right)^{2}}$,

where $g$ is gravitational acceleration, $T_{\mathrm{v}}$ is the average absolute virtual temperature, and $\partial \theta / \partial z$ is the vertical gradient of potential temperature, between the 68 and $329 \mathrm{~m}$ levels. The
Brunt-Väisälä frequency can be described as the upper frequency limit that a gravity wave can exceed. It was a calm quiescent night on 23 April 2009 with an average $R i$ of 4.31, a Brunt-Väisälä frequency of $0.0248 \mathrm{~s}^{-1}$ and $u *$ less than $0.2 \mathrm{~m} \mathrm{~s}^{-1}$ during the passage of the wave events. A triple decomposition Eq. (1) of the eddy-covariance data was applied to the periods identified in the wavelet analysis using the wave period range in a band-pass filter to obtain the wave signal for all variables. The quiescent night was disrupted by the passage of the wave, which induced large fluctuations in the time series as seen in Fig. 3 for the vertical velocity $(w)$ and $\mathrm{CO}_{2}$ concentration $(c)$ signals at the $34 \mathrm{~m}$ level. These fluctuations are observed in both the velocity components and scalar quantities beginning slightly before 04:00 LT and persisting until approximately 04:30 LT. This coincides with the strongest event detected using the wavelet analysis. These fluctuations create non-stationarity in the signal that can be resolved by removing the wave (Fig. 2c).

a different set of atmospheric conditions is presented on 3 December 2009. During that night, the average $R i$ was 0.42 and $\mathrm{u}^{*}$ exceeded $0.25 \mathrm{~m} \mathrm{~s}^{-1}$ for all three levels on the tower throughout the night. The resulting Brunt-Väisälä frequency was $0.0125 \mathrm{~s}^{-1}$ much higher than the approximate 
Table 2. Characterization of wave events and atmospheric conditions for the two case study nights including the duration of the wave event, the average wave period (min), the Brunt-Väisälä frequency $(N)$, the gradient Richardson number $(R i)$, and the friction velocity $(u *)$. Note that the friction velocity $(u *)$ is the ensemble $30 \mathrm{~min}$ average calculated over the duration of wave event at the $34 \mathrm{~m}$ level without filtering the wave signal.

\begin{tabular}{lrrrrr}
\hline Day of event & Duration & $\begin{array}{r}\text { Average } \\
\text { wave } \\
\text { period }\end{array}$ & $N$ & $R i$ & $u *$ \\
\hline 29 Apr 2009 & $02: 30-04: 30$ & 5.5 & 0.0248 & 4.31 & 0.11 \\
3 Dec 2009 & $03: 30-05: 30$ & 10 & 0.0125 & 0.42 & 0.51 \\
\hline
\end{tabular}
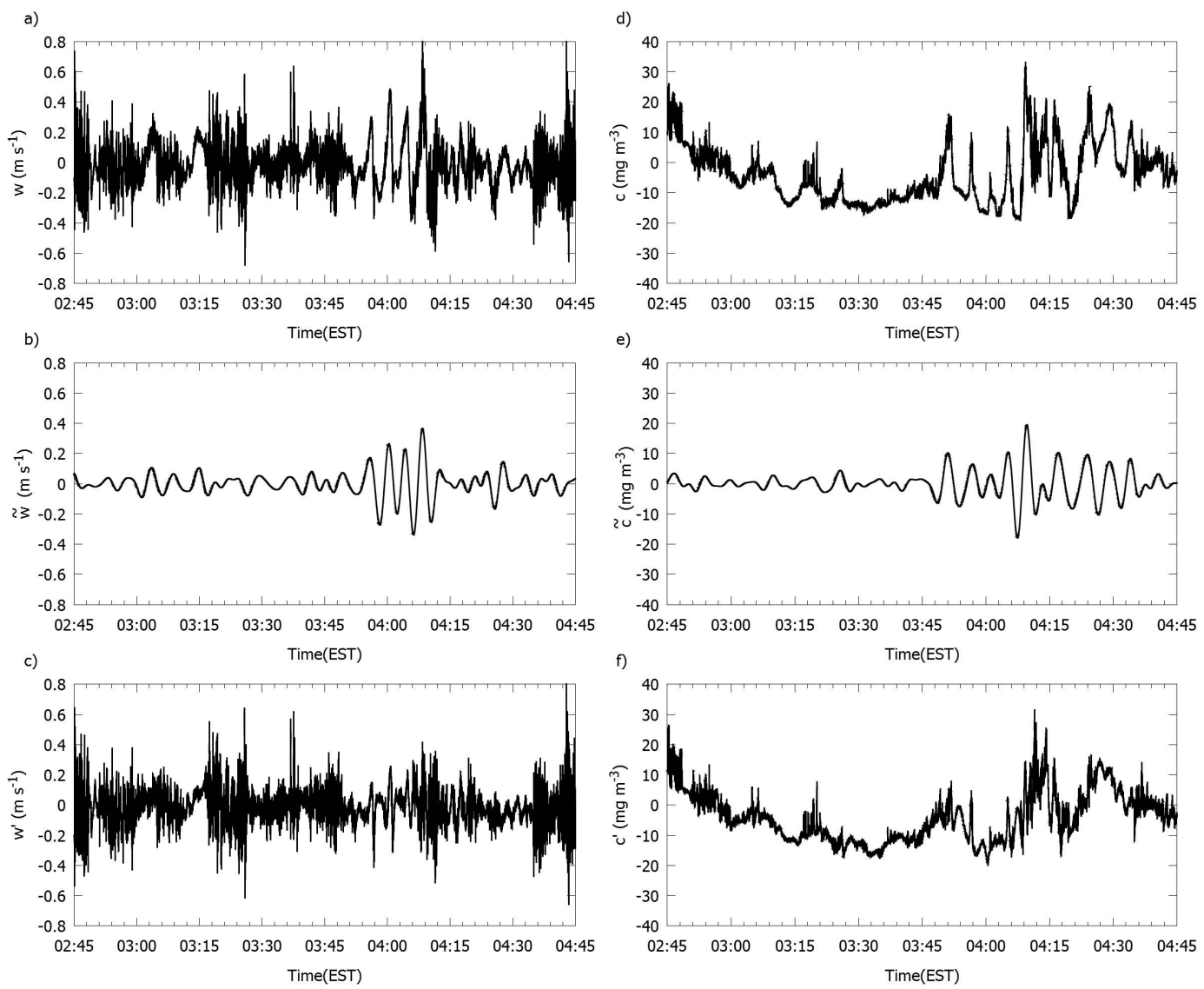

Fig. 2. Triple decomposition of variables $w$ and $\mathrm{CO}_{2}$ concentration $c$ are represented as detrended signals (a) $w$ and (d) $c$, wave signals (b) $w^{\prime}$ and (e) $c$ ', and turbulence signals (c) $w$ and (f) $c$ at the $34 \mathrm{~m}$ level on the tall tower on the night of 23 April 2009. Bottom figures represent the "corrected" turbulence signal.

frequency of the observed wave $\left(0.002 \mathrm{~s}^{-1}\right)$. The impact of the wave on the atmospheric variables can be seen; nevertheless, the impact observed is modest when compared to 23 April 2009. This is in part due to the larger amount of turbulence present simultaneously with the wave. The degree of error is inversely proportional to the turbulence levels present in the signal. The difference in the period of the waves observed on the two nights may also contribute to the differences observed.
Using the triple decomposition, the phase relationship between $\tilde{w}$ and $\tilde{T}$ at 34,68 , and $329 \mathrm{~m}$ for the observed periods is evaluated to identify whether the wave-like disturbance is indicative of a gravity wave. Also evident are the differences in amplitude, timing, and structure of the wave event with measurement level. Large differences in wave amplitudes and structures for each of these observation periods can be seen in Fig. 3a-f. Waves observed on 23 April have a higher frequency and amplitude. Figure 3 represents $\tilde{w}$ and $\tilde{T}$ for the three heights of the TV tower $(34,68$, and $329 \mathrm{~m})$. The 

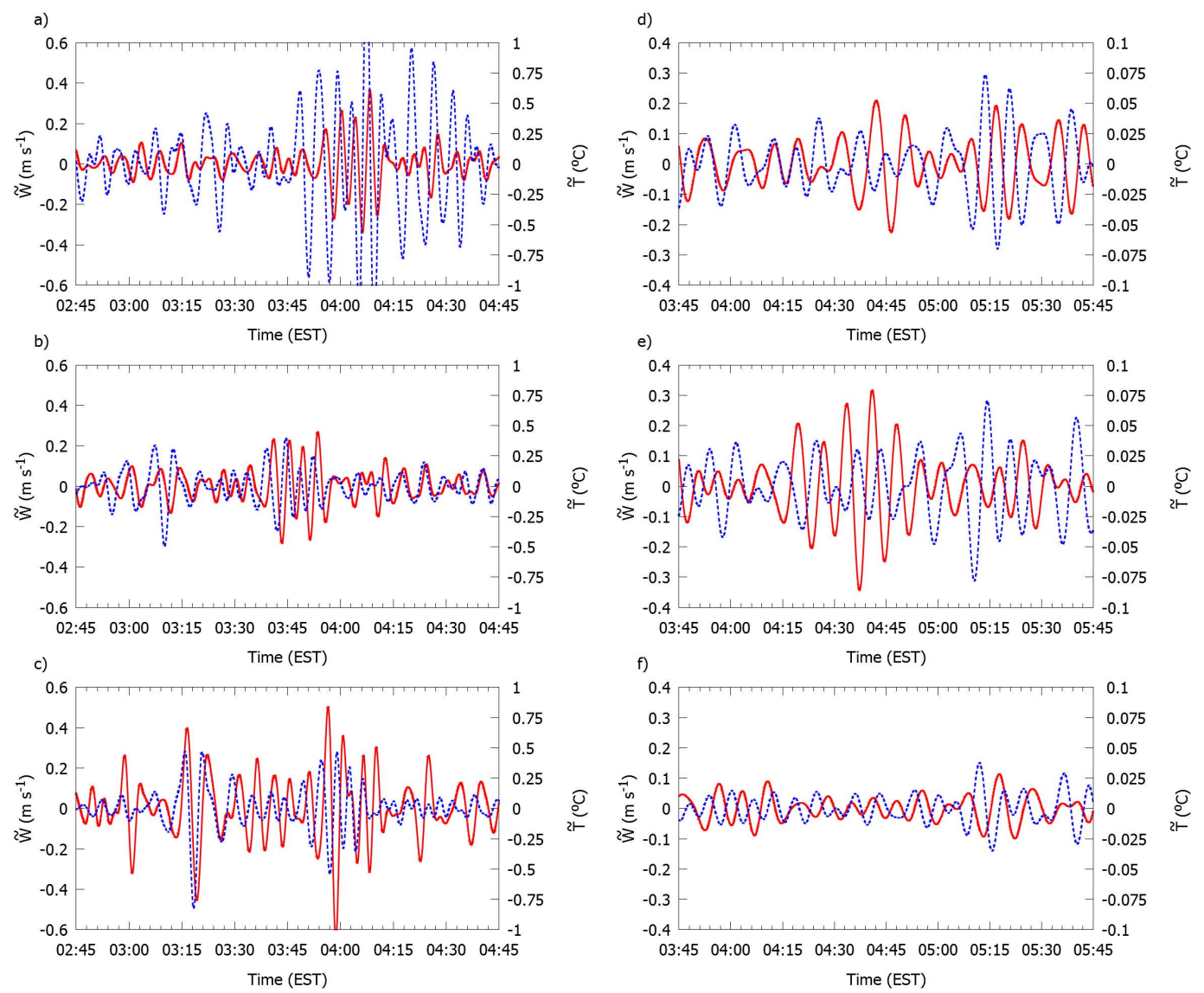

Fig. 3. $\tilde{w}$ (solid) and $\tilde{T}$ (dashed) at 34 (a, d), 68 (b, e), and 329 m (c, f) for 23 April 2009 and 3 December 2009.

phase relationship between $\tilde{w}$ and $\tilde{T}$ at the beginning of the wave activity is approximately $90^{\circ}$ on both 23 April 2009 and 3 December 2009 attesting to the presence of gravity waves each night. It is also evident that the waves are present at the $329 \mathrm{~m}$ level, suggesting that waves propagate throughout the nocturnal boundary layer.

\subsection{Wave-modified turbulence statistics and turbulent fluxes}

Nappo et al. (2008) found turbulence statistics to be consistently larger in the presence of gravity waves. Hence, the term "turbulence inflation" was ascribed to the phenomenon. The percent of turbulence inflation is defined as:

$\%$ Error $=\left(\frac{\text { "inflated" turbulent flux-"corrected" turbulent flux }}{\text { "inflated" turbulent flux }}\right)$

Turbulent fluxes were calculated using different averaging blocks. These calculations reveal the potential differences varying averaging blocks can have when calculating turbulent fluxes in the presence of wave phenomena and provide a quantitative estimate of the impact the wave event has throughout the duration of the event.
Turbulence statistics and turbulent fluxes were calculated using averaging blocks of 5, 10, 15, 30 and $60 \mathrm{~min}$. Values of "inflated" Turbulent Kinetic Energy (TKE) from the original signal, "corrected" TKE, and percent error are given for 23 April at $34 \mathrm{~m}$ (Fig. 4a-d) and $329 \mathrm{~m}$ (Fig. 4e-h). The turbulence statistics calculated in the presence of a wave are consistently inflated if the averaging time is longer than the wave period for the cases presented (Fig. 4), corroborating the findings of Nappo et al. (2008). However, Nappo et al. (2008) also found that for averaging times less than the wave period, wave perturbations had little impact on turbulence calculations. As shown in Fig. 4, it can be seen that inflation is present for averaging times longer than the period of wave event. For shorter averaging times, a modulation of the signal is observed with inflation observed in the form of localized bursts during the time of the wave events. It is interesting to note that the percentage turbulence inflation was consistent throughout all three levels on the tall tower despite much larger TKE values at the $329 \mathrm{~m}$ level. To further evaluate the impact of different averaging times, ensemble averages of turbulence statistics and fluxes for the entire wave event were calculated for the different averaging periods. 

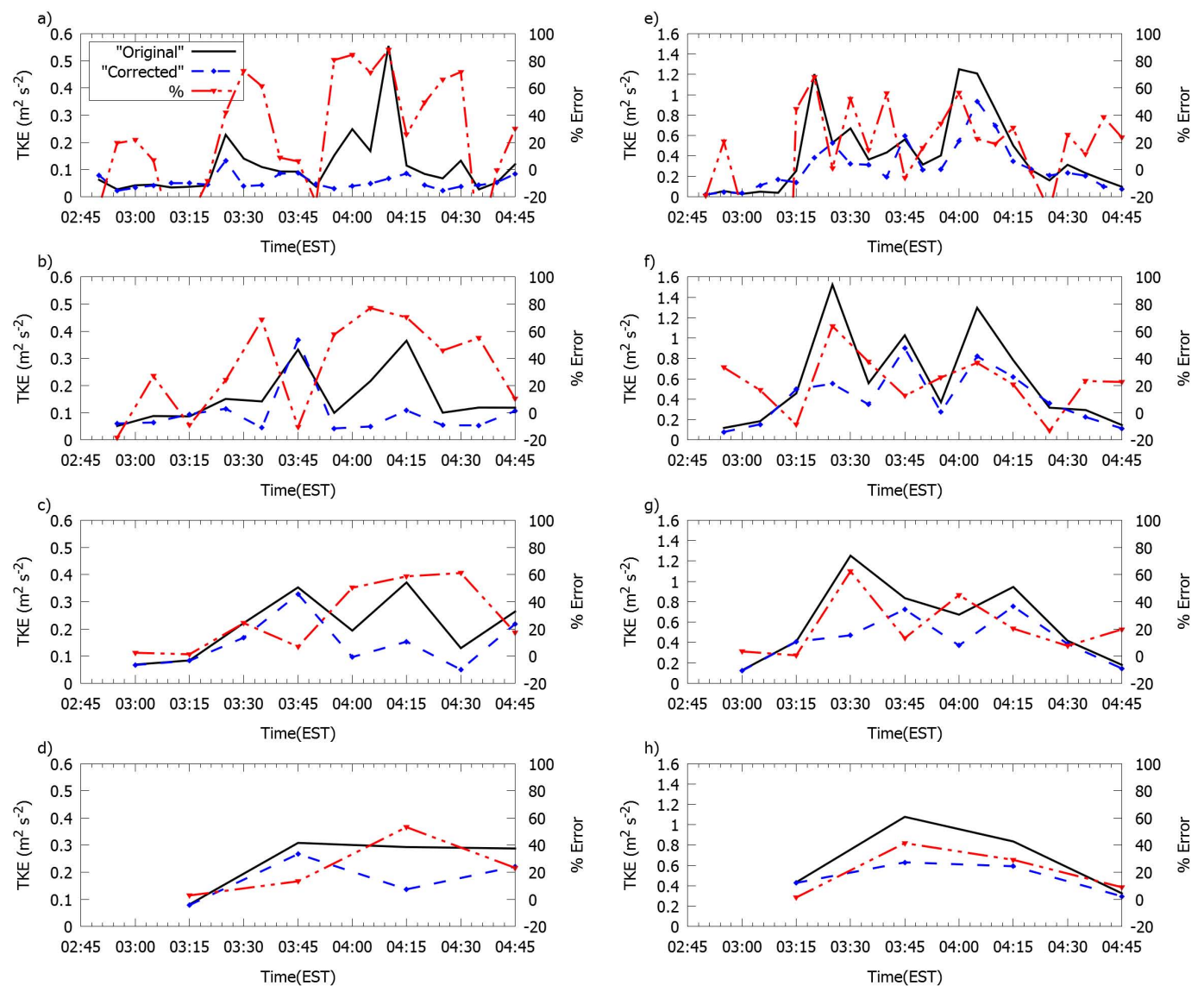

Fig. 4. Turbulent Kinetic Energy (TKE) calculations using the original signal (solid) and the corrected signal (dashed) after wave removal from the time series at 34 and $329 \mathrm{~m}$ levels on the tall tower using different averaging periods (5 (a, e), 10 (b, f), 15 (c, g), and 30 min (d, h)) on 23 April 2009. The percent error ("dot-dashed") is also presented.

Turbulent fluxes of heat, momentum, water vapor, and $\mathrm{CO}_{2}$ are not consistently inflated the way turbulence statistics are. Instead, fluxes are often modulated depending on the phase relationship of the calculated variables. Therefore, average "original" and "corrected" turbulent fluxes for the duration of the wave events were calculated, and an average percent difference was calculated:

Average $\%$ Error $=\left(\frac{\text { "original"turbulentflux }- \text { "corrected"turbulentflux }}{\text { "original"turbulentflux }}\right)$,

where the overbar represents averaging over the duration of the wave event. The averaged turbulence kinetic energy $(<\mathrm{TKE}\rangle)$, friction velocity $\left(\left\langle u^{*}\right\rangle\right), \mathrm{CO}_{2}$ flux $\left(\left\langle\mathrm{F}_{c}\right\rangle\right)$, and sensible heat flux $(<\mathrm{H}\rangle)$ are presented in Figs. 5a-h and $6 \mathrm{a}-$ $\mathrm{h}$, for the 34 and $329 \mathrm{~m}$ levels on the nights of 23 April and 3 December 2009, respectively.

The turbulence kinetic energy is overestimated on both nights for all averaging periods. However, the percent error is far greater on 23 April 2009, due to less ambient turbulence during the passage of the wave. $\mathrm{u}_{*}$ is also overestimated for all averaging times throughout all levels of the tall tower for each night as well, except for the $60 \mathrm{~min}$ average at the $329 \mathrm{~m}$ level on 23 April 2009 and 5 min average on 3 December 2009. The inflation observed at the $329 \mathrm{~m}$ level when shorter averages were used led to $\mathrm{u}_{*}$ exceeding the $0.25 \mathrm{~m} \mathrm{~s}^{-1}$ threshold, of significance to the flux community. This arbitrary threshold is often used in determining the validity of data in the nocturnal boundary layer (Aubinet, 2008, 2010; Falge et al., 2001; Goulden, 1996). The impact of the wave on $u_{*}$ is present at all heights on the tower producing differences of up to $30 \%$ for the shorter averaging periods at the 34 and $68 \mathrm{~m}$ levels on 23 April 2009. The difference is smaller with longer averaging periods, but nonetheless yields a difference of $10 \%$ for the $30 \mathrm{~min}$ average at both the 34 and $329 \mathrm{~m}$ levels. In contrast, 3 December is only marginally impacted due to large contributions from high frequencies and the mildly stable conditions.

On 3 December 2009, the $\mathrm{CO}_{2}$ and sensible heat fluxes are inflated for all averaging times at all levels on the tower by relatively small amounts $(<5 \%)$, though the degree of inflation is consistent amongst all variables evaluated (Fig. 6a-h). A somewhat special case is presented on 23 April 2009 as the sensible heat flux at the $34 \mathrm{~m}$ level is positive and the 
$\mathrm{CO}_{2}$ flux is negative, in contrast with typical nighttime flux tendencies (Fig. 5c). Zeri and Sa (2010) observed a similar behavior during the passage of a wave event in their study, which they attributed partially to the horizontal flux of $\mathrm{CO}_{2}$ induced by the wave. In our study, the magnitude of the negative $\mathrm{CO}_{2}$ flux is amplified by $15-30 \%$ for the longer averaging times $(15,30$, and $60 \mathrm{~min})$. These data suggest that a "contamination" of the signal by wave events leads to erroneous turbulence statistics and turbulent fluxes.

\subsection{Discussion}

Our preliminary study observed numerous large-amplitude wave-like events in the stable nocturnal boundary layer, and delved further into the effect of two large events on eddy-flux calculations. For the two nights studied, the impact of averaging time on the error observed in the calculations varies with the choice of the variables. Consistently, it was observed that taking longer averaging periods results in more robust estimations of TKE. The degree of error in $F_{c}$ varies both nights with averaging time. The error is generally small for averaging periods of $5 \mathrm{~min}$ and at its maximum for 10 to 15 min averaging periods. The error decreases for the longer averaging periods ranging between 30 to $60 \mathrm{~min}$. These results suggest that the wave frequency/period and its relation to the averaging period are important in determining the errors produced. The amount of the wave included in the averaging period varies as we typically tend to calculate data at easily discernible time periods, such as the beginning of the hour (i.e., 04:00 LT). Hence, these errors are primarily introduced through our processing methods through including partial wave cycles. This suggests that waves of different periods impact the turbulence statistics and flux calculations differently.

The impact of the wave on turbulence statistics and fluxes varies with height in the stable nocturnal boundary layer due to differences in turbulence and wave propagation properties. The variability in the amount of overestimation of turbulence statistics and errors in flux calculations appears to be relatively consistent with height when considering the percent error. However, when the values are considered, their differences become magnified. For instance, the TKE is much larger at the $329 \mathrm{~m}$ level than at the $34 \mathrm{~m}$ level. The impact of averaging time on the overestimation of turbulence statistics and errors in flux calculations varied with the choice of the examined variable. The variability in the percentage inflation of turbulence statistics and errors in turbulent flux calculations varies little with height. However, when the difference in the values of the turbulence statistics and turbulent fluxes are considered the amounts changed significantly. For instance, on 3 December 2009 the TKE values at the $34 \mathrm{~m}$ level were nearly double that measured at the $329 \mathrm{~m}$ level. Yet, the percentage inflation was very similar between the two levels, within $1 \%$ difference. Similar results were found on 23 April 2009 with the percentage of overestimation for the two measurement heights being similar, while the values of TKE are nearly double at the $329 \mathrm{~m}$ level.

Our findings suggest that, without proper filtering, turbulence statistics would be overestimated due to the presence of wave phenomena as found by Nappo et al. (2008) and Viena et al. (2009). Our study has also examined the role of filtering the wave component and has assessed the magnitude of errors introduced in turbulence statistics and turbulent fluxes on two nights with contrasting atmospheric conditions. On the relatively quiescent night, large overestimation of TKE and modulation of turbulent fluxes were found to occur during the passage of large-amplitude wave activity that introduced non-stationarity into the signal. The extent of the inflation and the sensitivity of the turbulence statistics and turbulent fluxes to various wave periods and amplitudes are unknown, thus suggesting a more exhaustive analysis. The possibility of restoring stationarity by removing the wave signal in cases with larger period waves is also intriguing and worthy of consideration in future studies.

The data used in the present study demonstrate that nights characterized by large TKE and $u_{*}\left(\sim 0.5 \mathrm{~m} \mathrm{~s}^{-1}\right)$ values are still impacted by the presence of the wave by a similar magnitude, but the percent error is not as large due to the larger amount of turbulence. When using a $u *$ threshold as a filtering parameter in net ecosystem exchange calculations, cases where $u *$ is approaching the threshold (typically $0.25 \mathrm{~m} \mathrm{~s}^{-1}$ ) may be biased by the presence of wave activity. The results do not directly translate into errors in long-term flux budgets; however, these slight impacts may influence the calculations through affecting stability classifications and $u *$ calculations. Also, the inclusion of partial wave cycles is almost inevitable when batch processing large amounts of data for seasonal or yearly budgets creating some errors, the extent of which should be quantified. A study to assess the impact on all the budget terms is necessary to separate wave contributions to flux budgets.

\section{Conclusions}

Large-amplitude wave-like events are likely to occur frequently at most sites, and should be examined during the processing of eddy-flux data. The present study showed that large-amplitude wave-like events (surpassing $3 \sigma$ threshold) occurred on $18 \%$ of the 216 nights studied. Both the frequency and intensity of wave-like events exhibit a seasonal dependence, increasing during the winter months at our site. Several cases determined to be large-amplitude gravity wave events impacted the calculation of both turbulence statistics and turbulent fluxes in the nocturnal boundary layer. Without proper filtering, inflated turbulence statistics of up to $50 \%$ and erroneous flux calculations may occur on quiescent nights. The presence of the wave also modulates the calculated turbulent fluxes of $\mathrm{CO}_{2}$, resulting in errors on the order of $10 \%$ over the duration of the wave depending on the 

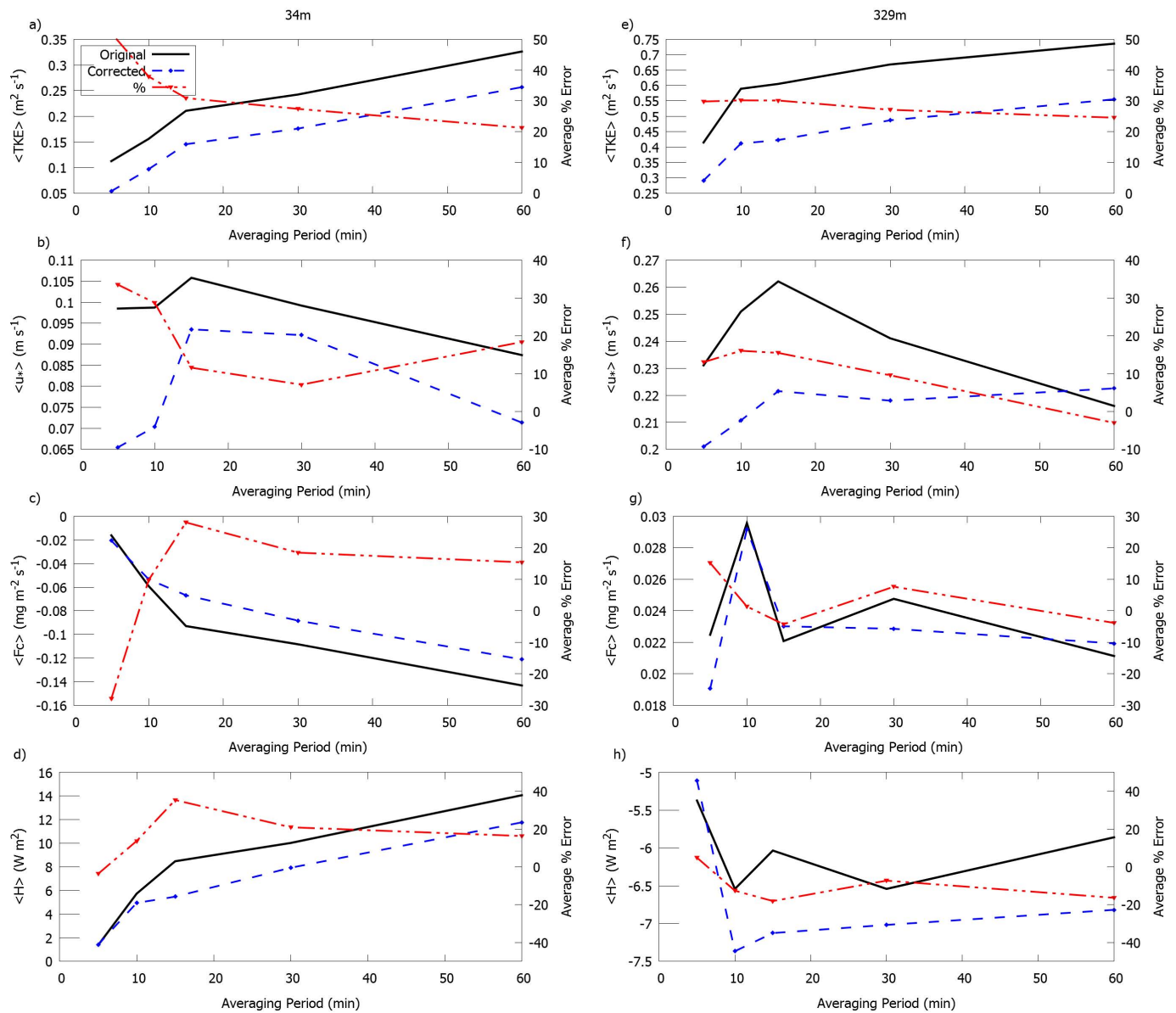

Fig. 5. Average turbulent kinetic energy $<\mathrm{TKE}>(\mathbf{a}, \mathbf{e})$, friction velocity $<u_{*}>(\mathbf{b}, \mathbf{f}), \mathrm{CO}_{2}$ flux $<F_{\mathrm{c}}>(\mathbf{c}, \mathbf{g})$, and sensible heat flux $<\mathrm{H}>(\mathbf{d}$, h) for the "original" (solid) and "corrected" (dashed) time series during the wave event on 23 April 2009 at the 34 and $329 \mathrm{~m}$ levels on the tall tower are depicted using different averaging periods. The average percent error (dot-dashed) introduced by the absence of such corrections is also displayed.

averaging time used. These errors persist in varying degrees, regardless of the selected averaging period.

The amount of the wave cycle included in an averaging period varies as we typically tend to calculate data at convenient time intervals, such as the beginning of the hour (i.e., 04:00 LT). These errors are primarily introduced through signal processing, including partial wave cycles into calculations. This suggests that waves of different periods impact the turbulence statistics and flux calculations differently and more work is needed to quantify the impact of including partial wave cycles in the averaging period. In addition, both $u *$ and the flux Richardson number $\left(R i_{\mathrm{f}}\right)$ are impacted by the presence of wave activity making typical classification of nighttime turbulence conditions inherently more difficult.

These results suggest that it is important to identify wave activity and remove them when calculating turbulence parameters and turbulent fluxes. Neglecting to do this is likely to lead to overestimated turbulence statistics and erroneous turbulent flux calculations. The implications could prove use- ful to modeling efforts attempting to calculate fluxes during stable nocturnal conditions. Furthermore, a climatological study seeking to determine the contributions of the wave signal to flux budgets is warranted. Interpreting wave-like events contributions to the various terms of the flux budget equation would provide further insight. With better determinations of wave contributions, model parameterizations of fluxes may improve. The present study has found a consistent overestimation of turbulence statistics for averaging times greater than the wave period. Cases where the wave period is greater than the averaging period exhibited errors as the results were modulated by the presence of the wave. 

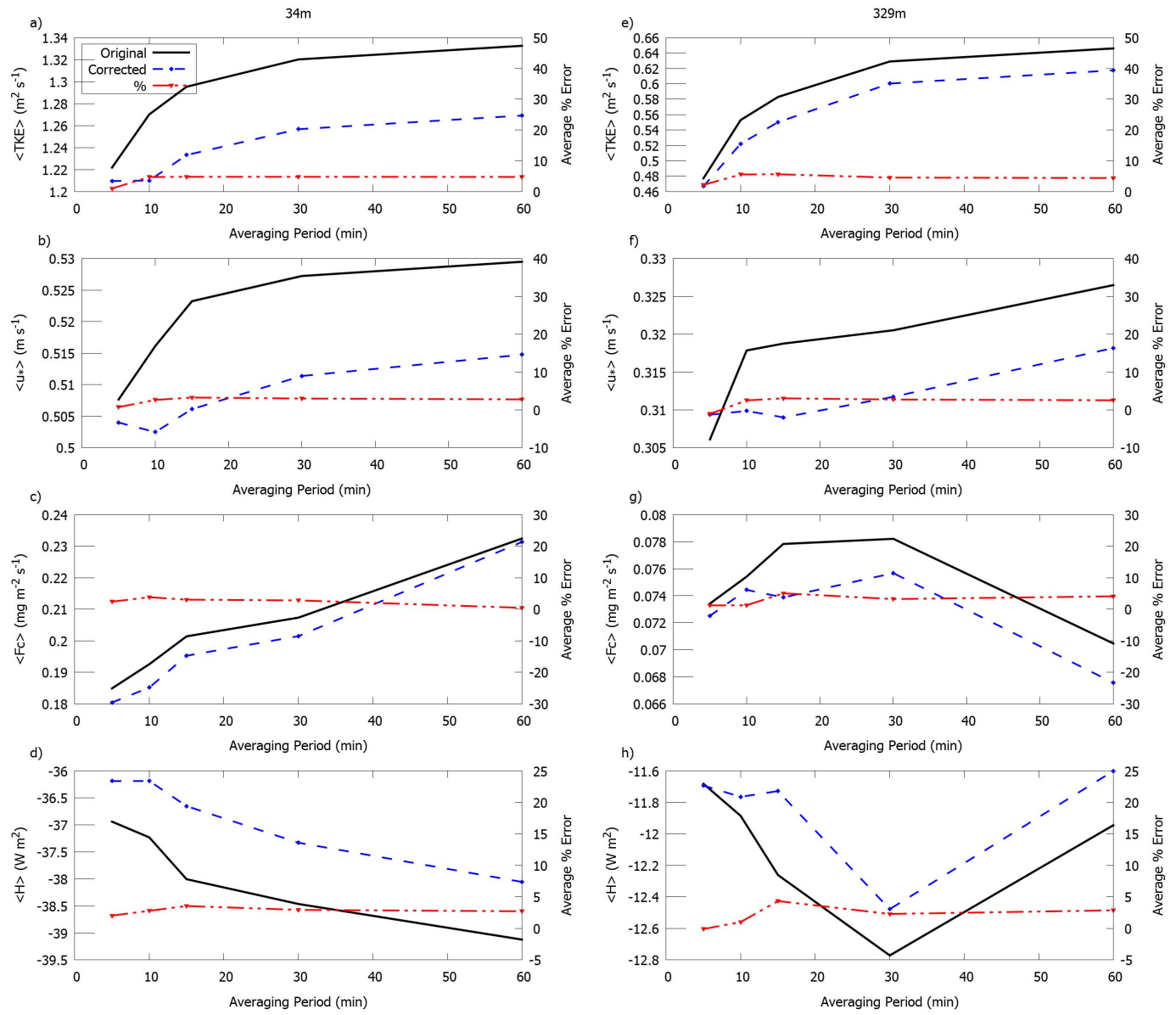

Fig. 6. Average turbulent kinetic energy $\langle\mathrm{TKE}\rangle(\mathbf{a}, \mathbf{e})$, friction velocity $\left\langle u_{*}\right\rangle(\mathbf{b}, \mathbf{f}), \mathrm{CO}_{2}$ flux $\left\langle\mathrm{F}_{\mathrm{c}}\right\rangle(\mathbf{c}, \mathbf{g})$, and sensible heat flux $\langle\mathrm{H}\rangle(\mathbf{d}$, h) for the "original" (solid) and "corrected" (dashed) time series during the wave event on 3 December 2009 at the 34 and $329 \mathrm{~m}$ levels on the tall tower are depicted using different averaging periods. The average percent error (dot-dashed) introduced by the absence of such corrections is also displayed.

Acknowledgements. We wish to extend our thanks for D. Cotten for his input and useful comments on the manuscript as well. The present study was conducted thanks to a grant from the US Dept. of Energy, Office of Science, Terrestrial Carbon Processes grant no. ER64321.

Edited by: E. Falge

\section{References}

Aubinet, M.: Eddy covariance $\mathrm{CO}_{2}$ flux measurements in nocturnal conditions: An analysis of the problem, Ecol. Appl., 18, 13681378, 2008.

Aubinet, M.: Direct $\mathrm{CO}_{2}$ advection measurements and the night flux problem, Agr. Forest Meteorol., 150, 651-654, 2010.

Chimonas, G.: Surface drag instabilities in the atmospheric boundary-layer, J. Atmos. Sci., 50, 1914-1924, 1993.

Chimonas, G.: Steps, waves and turbulence in the stably stratified planetary boundary layer, Bound.-Lay. Meteorol., 90, 397-421, 1999.
Cooper, D. I., Leclerc, M. Y., Archuleta, J., Coulter, R., Eichinger, E. W., Kao, C. Y. J., and Nappo, C. J.: Mass exchange in the stable boundary layer by coherent structures, Agr. Forest Meteorol., 136, 114-131, 2006.

Einaudi, F. and Finnigan, J. J.: The interaction between an internal gravity wave and the planetary boundary Layer, Pt. I: The Linear Analysis, Q. J. Roy. Meteor. Soc., 107, 793-806, 1981.

Einaudi, F. and Finnigan, J. J.: Wave-turbulence dynamics in the stably stratified boundary layer, J. Atmos. Sci., 50, 1841-1864, 1993.

Einaudi, F., Finnigan, J. J., and Fua, D.: Gravity wave turbulence interaction in the presence of a critical level, J. Atmos. Sci., 41, 661-667, 1984.

Emmanuel, C. B.: Richardson number profiles through shear instability wave regions observed in the lower planetary boundary layer, Bound.-Lay. Meteorol., 5, 19-27, 1973.

Falge, E., Baldocchi, D., Olson, R., Anthoni, P., Aubinet, M., Bernhofer, C., Burba, G., Ceulemans, R., Clement, R., and Dolman, H.: Gap filling strategies for long term energy flux data sets, Agr. Forest Meteorol., 107, 71-77, 2001. 
Finnigan, J. J.: Kinetic energy transfer between internal gravity waves and turbulence, J. Atmos. Sci., 45, 486-505, 1988.

Finnigan, J. J.: A note on wave-turbulence interaction and the possibility of scaling the very stable boundary layer, Bound.-Lay. Meteorol., 90, 529-539, 1999.

Finnigan, J. J. and Einaudi, F.: The interactions between an internal gravity wave and the planetary boundary layer, Pt. II: Effect of the wave on the turbulence structure, Q. J. Roy. Meteor. Soc., 107, 807-832, 1981.

Fritts, D. C., Nappo, C., Riggin, D. M., Balsley, B. B., Eichinger, W. E., and Newsom, R. K.: Analysis of ducted motions in the stable nocturnal boundary layer during CASES-99, J. Atmos. Sci., 60, 2450-2472, 2003.

Gedzelman, S. D.: Short-period atmospheric gravity-waves - A study of their statistical properties and source mechanisms, Mon. Weather Rev., 111, 1293-1299, 1983.

Gossard, E. E. and Hooke, W. H.: Waves in the atmosphere, Elsevier Scientific Publishing, New York, 1975.

Goulden, M. L., Munger, J. W., Fan, S.-M., Daube, B. C., and Wofsy, S. C.: Measurements of carbon sequestration by longterm eddy covariance: method and a critical evaluation of accuracy, Glob. Change Biol., 2, 169-182, 1996.

Grivet-Talocia, S., Einaudi, F., Clark, W. L., Dennett, R. D., Nastrom, G. D., and VanZandt, T. E.: A 4 yr climatology of pressure disturbances using a barometer network in central Illinois, Mon. Weather Rev., 127, 1613-1629, 1999.

Hauf, T., Finke, U., Neisser, J., Bull, G., and Stangenberg, J.-G.: A ground-based network for atmospheric pressure fluctuations, J. Atmos. Ocean. Tech., 13, 1001-1023, 1996.

Hooke, W., Hall, F., and Gossard, E.: Observed generation of an atmospheric gravity wave by shear instability in the mean flow of the planetary boundary layer, Bound.-Lay. Meteorol., 5, 2941, 1973.

Karipot, A., Leclerc, M. Y., Zhang, G., Lewin, K. F., Nagy, J., Hendrey, G. R., and Starr, G.: Influence of nocturnal lowlevel jet on turbulence structure and $\mathrm{CO}_{2}$ flux measurements over a forest canopy, J. Geophys. Res.-Atmos., 113, D10102, doi:10.1029/2007JD009149, 2008.

Mahrt, L.: Stratified atmospheric boundary layers, Bound.-Lay. Meteorol., 90, 375-396, 1999.
Mahrt, L.: Common microfronts and other solitary events in the nocturnal boundary layer, Q. J. Roy. Meteor. Soc., 136, 17121722, 2010.

Mathieu, N., Strachan, I. B., Leclerc, M. Y., Karipot, A., and Pattey, E.: Role of low-level jets and boundary-layer properties on the NBL budget technique, Agr. Forest Meteorol., 135, 35-43, 2005.

Nappo, C. J.: An Introduction to Atmospheric Gravity Waves, Academic Press, New York, 2002.

Nappo, C. J., Miller, D. R., and Hiscox, A. L.: Wave-modified flux and plume dispersion in the stable boundary layer, Bound.-Lay. Meteorol., 129, 211-223, 2008.

Newsom, R. K. and Banta, R. M.: Shear-flow instability in the stable nocturnal boundary layer as observed by Doppler lidar during CASES-99, J. Atmos. Sci., 30, 16-33, 2003.

Rees, J. M. and Mobbs, S. D.: Studies of internal gravity waves at Halley Base, Antarctica, using wind observations, Q. J. Roy. Meteor. Soc., 114, 939-966, 1988.

Rees, J. M., Denholm-Price, J. C. W., King, J. C., and Anderson, P. S.: A climatological study of internal gravity waves in the atmospheric boundary layer, J. Atmos. Sci., 57, 511-526, 2000.

Torrence, C. and Compo, G. P.: A practical guide to wavelet analysis, B. Am. Meteorol. Soc., 79, 61-78, 1998.

van Gorsel, E., Harman, I. N., Finnigan, J. J., and Leuning, R.: Decoupling of air flow above and in plant canopies and gravity waves affect micrometeorological estimates of net scalar exchange, Agr. Forest Meteorol., 151, 927-933, 2011.

Viana, S., Yagüe, C., and Maqueda, G.: Propagation and effects of a mesoscale gravity wave over a weakly-stratified nocturnal boundary layer during the SABLES2006 field campaign, Bound.-Lay. Meteorol., 133, 165-188, 2009.

Webb, E. K., Pearman, G. I., and Leuning, R.: Correction of flux measurements for density effects due to heat and water vapour transfer, Q. J. Roy. Meteor. Soc., 106, 85-100, 1980.

Zeri, M. and Sa, L. D. A.: Horizontal and vertical turbulent fluxes forced by a gravity wave event in the nocturnal atmospheric surface layer over the Amazon forest, Bound.-Lay. Meteorol., 138, 413-431, 2011. 